\title{
Synthesis of diisopropylcyclopropenone and X-ray structure of its dichlorodimethyltin(IV) adduct
}

\author{
Owen J. Curnow,* Glen M. Fern, and Robert J. Pipal \\ Department of Chemistry, University of Canterbury, Private Bag 4800, Christchurch \\ New Zealand \\ E-mail: owen.curnow@,canterbury.ac.nz
}

Dedicated to Professor James M. Coxon on his $65^{\text {th }}$ birthday

\begin{abstract}
Diisopropylcyclopropenone was prepared by a dehydrobromination of 3,5-dibromo-2,6dimethylheptan-4-one and isolated in $18 \%$ yield via an aqueous extraction procedure. It was characterised by an X-ray crystal structure analysis of its complex with dichlorodimethyltin(IV): Dichlorodimethyl(diisopropylcyclopropenone)tin(IV) was found to have a chloro-bridged dimeric structure in the solid state.
\end{abstract}

Keywords: Crystal structure, cyclopropenone, tin complex

\section{Introduction}

Dialkylcyclopropenones have been studied extensively and are used in the preparation of compounds such as phosphatriafulvenes, vinylcyclopropenes, and cyclopropenium salts. ${ }^{1}$ The most versatile route to cyclopropenones involves the dehydrobromination of $\alpha, \alpha$ '-dihaloketones by a modified Favorskii reaction. ${ }^{2}$ We had noted that the precursor to prepare the $\alpha, \alpha^{\prime}-$ dihaloketone for conversion to diisopropylcyclopropenone (1), 2,6-dimethyl-4-heptanone, is significantly cheaper than the precursor for the ditertbutyl analogue, 2,2,6,6-tetramethyl-4heptanone, and since we would expect the diisopropyl analogue 1 to be particularly useful due to the additional stereochemical information that isopropyl groups can provide, we were surprised that the only reference to $\mathbf{1}$ occurs in a 1969 paper by Ciabattoni and Nathan. ${ }^{3}$ This paper states only that it can be prepared by a modified Favorskii reaction of di(bromo-iso-butyl)ketone in a $20 \%$ yield and has a boiling point of $70-72{ }^{\circ} \mathrm{C}$ at $0.3 \mathrm{mmHg}$. In this paper we report the preparation, isolation and characterisation of diisopropylcyclopropenone and the structure of its dichlorodimethyltin(IV) complex. 


\section{Results and Discussion}

Dehydrobromination of 3,5-dibromo-2,6-dimethylheptan-4-one was carried out using sodium hydride in tetrahydrofuran followed by addition of aqueous hydrochloric acid. Typical procedures for the isolation of cyclopropenones involve an extraction of the organics using diethyl ether or petroleum ether. We found that this procedure, however, gave none of the desired product. Collection of the aqueous layer followed by extraction with a more polar organic solvent, such as dichloromethane, did, however, give us our desired cyclopropenone. Apparently, $\mathbf{1}$ is more soluble in water than in diethyl ether or petroleum ether.

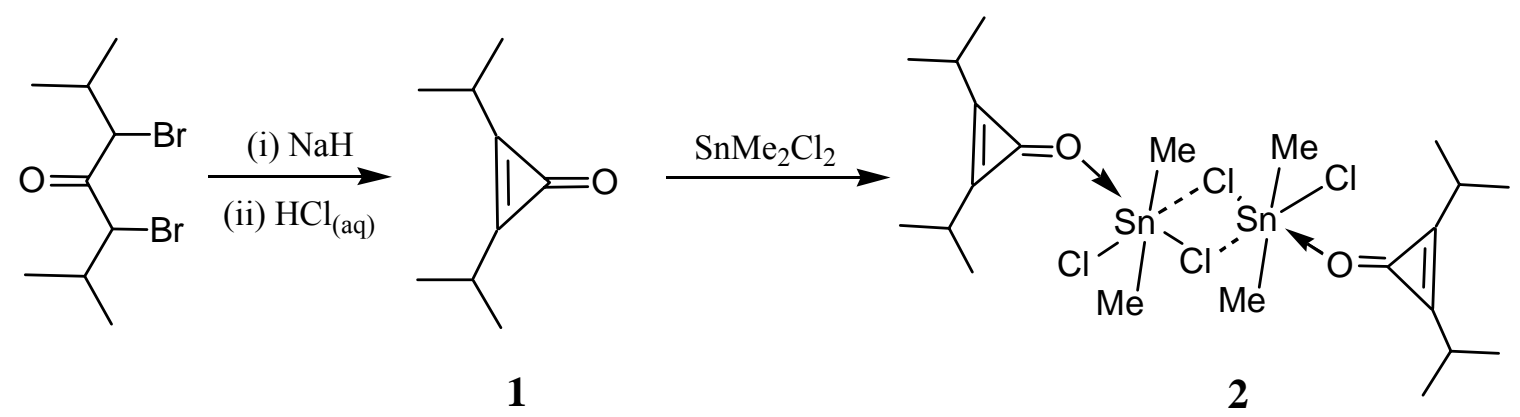

Scheme 1

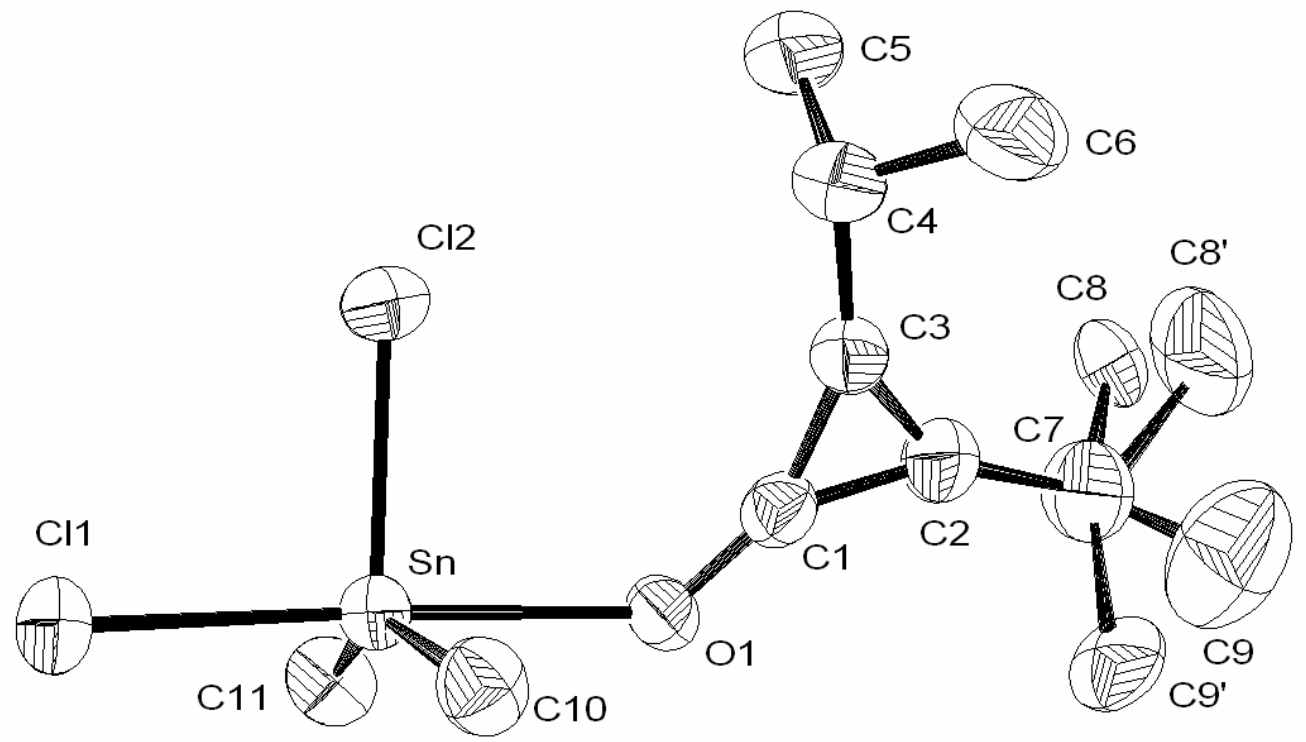

Figure 1. ORTEP of the asymmetric unit of compound 2 (30\% probability ellipsoids). Selected bond distances $(\AA)$ and angles $\left(^{\circ}\right)$ : $\mathrm{C}(1)-\mathrm{O}(1) 1.229(6), \mathrm{C}(1)-\mathrm{C}(2) 1.379(7), \mathrm{C}(2)-\mathrm{C}(3)$ 1.334(8), $\mathrm{C}(1)-\mathrm{C}(3)$ 1.388(8), C(3)-C(4) 1.491(8), C(2)-C(7) 1.499(6), Sn-O(1) 2.366(4), Sn-Cl(1) 2.4822(16), Sn-Cl(2) 2.3765(14), Sn-C(10) 2.092(6), Sn-C(11) 2.091(5), Sn-Cl(1') 3.5040(16), $\mathrm{Sn}-\mathrm{O}(1)-\mathrm{C}(1)$ 130.5(3), Cl(1)-Sn-Cl(1') 81.82(5), Sn-Cl(1)-Sn’ 98.18(5). 
${ }^{1} \mathrm{H}$ - and ${ }^{13} \mathrm{C}-\mathrm{NMR}$ spectra are consistent with the expected cyclopropenone 1 . There are two diagnostic bands in an infrared spectrum of a cyclopropenone that occur in the ranges of 1890$1800 \mathrm{~cm}^{-1}$ and $1660-1600 \mathrm{~cm}^{-1}$. These are due to coupled vibrations of the $\mathrm{C}=\mathrm{O}$ and $\mathrm{C}=\mathrm{C}$ double bonds. For 1 , these were observed at $1838 \mathrm{~cm}^{-1}$ and $1624 \mathrm{~cm}^{-1}$.

The oily nature of our material hindered us from obtaining a good microanalytical result, so we sought to further confirm the identity of $\mathbf{1}$ by the synthesis of a coordination compound. Mixing chloroform solutions of $\mathbf{1}$ and dichlorodimethyltin(IV) produced, upon evaporation of the solvent, large colourless crystals of $\mathrm{Me}_{2} \mathrm{SnCl}_{2} \cdot \mathrm{O}=\mathrm{CC}_{2}(i-\mathrm{Pr})_{2}(2)$. The expected 1:1 nature of the complex was confirmed by a single-crystal X-ray diffraction study. As shown in Figure 1, the tin complex exists in the solid state as a weak dimer, with long intermolecular chloro-bridging ligands. The centre of the dimer is a planar $\mathrm{Sn}_{2} \mathrm{Cl}_{2}$ ring with two long $\mathrm{Sn}-\mathrm{Cl}$ bonds (ca. $3.50 \AA$ ), and two short $\mathrm{Sn}-\mathrm{Cl}$ bonds (ca. $2.48 \AA$ ). A centre of inversion through the $\mathrm{Sn}_{2} \mathrm{Cl}_{2}$ ring relates each monomeric unit to the other. This dimerisation allows the tin atoms to adopt a conventional octahedral geometry, with the carbonyl oxygen trans to the short $\mathrm{Sn}-\mathrm{Cl}$ bond of the one of the bridging chloro ligands. This structure is similar to that found for the diphenylcyclopropenone analogue. $^{5}$

We have reported the successful preparation and isolation of diisopropylcyclopropenone via an unexpected aqueous-extraction method which will facilitate its use in further chemistry.

\section{Experimental Section}

General Procedures. All manipulations and reactions were carried out under an inert atmosphere by use of standard Schlenk line techniques. Reagent grade tetrahydrofuran was distilled prior to use from $\mathrm{Na}$ /benzophenone; chloroform was saturated with dinitrogen prior to use. 3,5-Dibromo-2,6-dimethylheptan-4-one was prepared by bromination of 2,6dimethylheptan-4-one. ${ }^{6}$ All other reagents were used as supplied by Aldrich Chemical Company. ${ }^{1} \mathrm{H}$ - and ${ }^{13} \mathrm{C}\left\{{ }^{1} \mathrm{H}\right\}$-NMR data were collected on a Varian XL-300 spectrometer operating at 300 and $75 \mathrm{MHz}$, respectively. Spectra were measured at ambient temperature with residue solvent peaks as internal standard. EI and FAB mass spectra were collected on a Kratos MS80RFA mass spectrometer. IR spectra were obtained on a Shimadzu FTIR-8201PC spectrophotometer. Elemental analyses were done by Campbell Microanalysis Services at Otago University, Dunedin.

Diisopropylcyclopropenone (1). At $-80{ }^{\circ} \mathrm{C}$, $\mathrm{NaH}$ (4.606 g of $60 \%$ suspension in oil, 115.2 mmol) was added to 3,5-dibromo-2,6-dimethylheptan-4-one $(17.191 \mathrm{~g}, 57.3 \mathrm{mmol})$ in tetrahydrofuran $(120 \mathrm{~mL})$ over a period of three hours. The resulting mixture was stirred overnight at ambient temperature. The mixture was then cooled to $-80{ }^{\circ} \mathrm{C}$ and $10 \mathrm{~mL}$ of $10 \%$ $\mathrm{HCl}_{(\mathrm{aq})}$ was added drop-wise. The solution was allowed to warm to ambient temperature and the precipitated salts were filtered off and washed with tetrahydrofuran $(2 \times 20 \mathrm{~mL})$. The washings and filtrate were combined, and the tetrahydrofuran was removed in vacuo. The resulting yellow 
oil was redissolved in petroleum ether and any residual $\mathrm{NaBr}$ filtered off. The cyclopropenone was extracted with portions of water $(2 \times 100 \mathrm{~mL})$ and then extracted from the water with $\mathrm{CH}_{2} \mathrm{Cl}_{2}(2 \times 100 \mathrm{~mL})$. The solvent was removed in vacuo to leave a pale yellow oil (1.46 g, 18\%). FT-IR: $v_{\max } / \mathrm{cm}^{-1}\left(\mathrm{CH}_{2} \mathrm{Cl}_{2}\right) 1838(\mathrm{~s}), 1624(\mathrm{~s}) .{ }^{1} \mathrm{H}-\mathrm{NMR}\left(\mathrm{CDCl}_{3}\right): \delta 2.76$ (septet, ${ }^{3} \mathrm{~J}=7 \mathrm{~Hz}$, $\left.2 \mathrm{H}, \mathrm{CH}\left(\mathrm{CH}_{3}\right)_{2}\right), 1.09\left(\mathrm{~d},{ }^{3} \mathrm{~J}=7 \mathrm{~Hz}, 12 \mathrm{H}, \mathrm{CH}\left(\mathrm{CH}_{3}\right)_{2}\right) .{ }^{13} \mathrm{C}-\mathrm{NMR}\left(\mathrm{CDCl}_{3}\right): \delta 163.4(\mathrm{C}=\mathrm{C}), 159.3$ $(\mathrm{C}=\mathrm{O}), 27.1\left(\mathrm{CHMe}_{2}\right), 20.2\left(\mathrm{CH}_{3}\right)$. Mass spectrum $m / z(\mathrm{EI}) 138\left(20, \mathrm{M}^{+}\right), 95\left(100,\left[\mathrm{M}-{ }^{\mathrm{i}} \mathrm{Pr}\right]^{+}\right)$, $67\left(95, \mathrm{C}_{5} \mathrm{H}_{7}^{+}\right), 55\left(40, \mathrm{C}_{3} \mathrm{H}_{3} \mathrm{O}^{+}\right)$.

Dichlorodimethyl(diisopropylcyclopropenone)tin(IV) (2). Diisopropylcyclopropenone (0.574 g, $4.15 \mathrm{mmol})$ was added drop-wise to a solution of $\mathrm{Me}_{2} \mathrm{SnCl}_{2}(0.455 \mathrm{~g}, 2.07 \mathrm{mmol})$ in chloroform $(30 \mathrm{~mL})$. The mixture was stirred for 30 minutes, and the chloroform was then slowly evaporated off to give colourless crystals (0.656 g, yield at least 89\%). m.p. $42-46{ }^{\circ} \mathrm{C}$. FT-IR: $v_{\max } / \mathrm{cm}^{-1}\left(\mathrm{CH}_{2} \mathrm{Cl}_{2}\right) 1838(\mathrm{~s}), 1585$ (s). ${ }^{1} \mathrm{H}-\mathrm{NMR}\left(\mathrm{CDCl}_{3}\right): \delta 3.02$ (septet, ${ }^{3} \mathrm{~J}=7 \mathrm{~Hz}, 2 \mathrm{H}$, $\left.\mathrm{C} H\left(\mathrm{CH}_{3}\right)_{2}\right), 1.29\left(\mathrm{~d},{ }^{3} \mathrm{~J}=7 \mathrm{~Hz}, 12 \mathrm{H}, \mathrm{CH}\left(\mathrm{CH}_{3}\right)_{2}\right), 1.1\left(\mathrm{~s}, 6 \mathrm{H}, \mathrm{Sn}-\mathrm{CH}_{3}\right) .{ }^{13} \mathrm{C}-\mathrm{NMR}\left(\mathrm{CDCl}_{3}\right): \delta$ $163.5(\mathrm{C}=\mathrm{C}), 160.3(\mathrm{C}=\mathrm{O}), 27.2\left(\mathrm{CHMe}_{2}\right), 20.2\left(\mathrm{CH}_{\left.\left(\mathrm{CH}_{3}\right)_{2}\right),}, 8.8\left(\mathrm{SnCH}_{3}\right)\right.$. Mass spectrum $\mathrm{m} / z$ $(\mathrm{FAB}) 461 \quad\left(10, \quad\left[\mathrm{SnMe}_{2} \mathrm{Cl}\left({ }^{\mathrm{i}} \mathrm{Pr}_{2} \mathrm{C}_{2} \mathrm{CO}\right)_{2}\right]^{+}\right), 323 \quad\left(46, \quad\left[\mathrm{SnMe}_{2} \mathrm{Cl}\left({ }^{\mathrm{i}} \mathrm{Pr}_{2} \mathrm{C}_{2} \mathrm{CO}\right)\right]^{+}\right), \quad 277 \quad$ (96, $\left.\left[\left({ }^{\mathrm{i}} \mathrm{Pr}_{2} \mathrm{C}_{3} \mathrm{O}\right)_{2} \mathrm{H}\right]^{+}\right), 139\left(100,\left[{ }^{\mathrm{i}} \mathrm{Pr}_{2} \mathrm{C}_{2} \mathrm{COH}\right]^{+}\right)$. Anal. Calcd for $\mathrm{C}_{11} \mathrm{H}_{20} \mathrm{Cl}_{2} \mathrm{OSn}$ : C, 36.92; H, 5.63. Found C, 37.00; H, 5.71.

Crystallography. X-ray crystallographic data for 2 was collected from a single crystal sample $(0.7 \times 0.7 \times 0.35 \mathrm{~mm})$, which was mounted on a glass fibre. Data was collected using a Bruker SMART $1 \mathrm{~K}$ CCD area detector diffractometer (using the program $\mathrm{SMART}^{7}$ ) and graphite monochromated Mo-K $\alpha$ radiation $(\lambda=0.71073 \AA)$. Processing was carried out by use of the program $\mathrm{SAINT}^{7}$ which applied Lorentz and polarisation corrections to three-dimensionally integrated diffraction spots. The program $\mathrm{SADABS}^{8}$ was utilised for the scaling of diffraction data, the application of a decay correction, and empirical absorption correction based on redundant reflections. The structure for 2 was solved by the direct methods procedure in the SHELXTL program library. ${ }^{9}$ The structures were refined by least-squares methods on $F^{2}$ with anisotropic thermal parameters for all non-hydrogen atoms. Hydrogen atoms were added as riding contributors at calculated positions, with isotropic thermal parameters based on the attached carbon atom. One isopropyl group is disordered and was modelled as two isopropyls with different site occupancies and with $\mathrm{C} 7$ and $\mathrm{C} 7$ ' constrained to have the same position and thermal parameters.

Crystal data for compound 2. $\mathrm{C}_{11} \mathrm{H}_{20} \mathrm{Cl}_{2} \mathrm{OSn}, M=357.86$, orthorhombic, $a=12.8756(14), b=$ 10.5637(11), $c=23.081(2) \AA, V=3139.3(6) \AA^{3}, D_{\mathrm{c}}=1.514 \mathrm{~g} \mathrm{~cm}^{-3}, \mu=1.946 \mathrm{~mm}^{-1}, F(000)=$ $1424, T=293(2) \mathrm{K}$, space group $P$ bca, $Z=8,10115$ reflections measured $\left(\theta=2.37\right.$ to $26.38^{\circ}$ ), 2976 unique $\left(R_{\text {int }}=0.0273\right), R_{1}=0.0362(I>2 \sigma(I)), w R_{2}=0.11045$ (all data), largest difference peak and hole 0.558 and -0.494 e. $\AA^{-3}$. Full crystallographic details were deposited at the Cambridge Crystallographic Data Centre with number CCDC 253372. 


\section{References}

1. Komatsu, K.; Kitagawa, T. Chem. Rev. 2003, 103, 1371.

2. Breslow, R.; Posner, J.; Krebs, A. J. Am. Chem. Soc. 1963, 85, 234.

3. Ciabattoni, J.; Nathan, E.C. Tetrahedron Lett. 1969, 57, 4997.

4. (a) Briggs, E.M.; Bird C.W.; Harmer, A.F. Spectrochim. Acta, Part A 1969, 25, 1319; (b) Krebs, A.; Schrader, B. Liebigs Ann. Chem. 1967, 709, 46; (c) Brown, F.R.; Finseth, D.H.; Miller F.A.; Rhee, K.H. J. Am. Chem. Soc. 1975, 97, 1011; (d) Krebs, A.; Schrader B.; Höfler, F. Tetrahedron Lett. 1968, 5935.

5. Ng, S.W.; Barnes, C.L.; Hossain, M.B.; Van der Helm, D.; Zuckerman J.J.; Kumar Das, V.G. J. Am. Chem. Soc. 1982, 104, 5359.

6. Lion, C.; Dubois, J.-E. Tetrahedron 1975, 31, 1223.

7. SMART and SAINT. Siemens Analytical, Madison, WI, 1997.

8. SADABS version 2.03, G.M. Sheldrick, University of Göttingen, Germany, 2002.

9. SHELXTL version 5.1., G.M. Sheldrick, Bruker AXS, Madison, WI, 1998. 